\title{
Effect of implementing rehabilitation program on knowledge, physical and psychological function of patients had lower limb amputation
}

\author{
Neama Mamdouh Mostafa, Zienab Abd El-Lateef Mohamed, Sonia Mohamed Rashad \& Ayman Sayed Abd \\ Elsalam
}

Assistant lecturer of Adult Nursing, Faculty of Nursing, Assiut University, Egypt.

Professor of Medical Surgical Nursing, Faculty of Nursing, Assiut University, Egypt.

Professor of physical therapy, Faculty of Medicine, Assiut University, Egypt.

Assistant professor of Vascular surgery, Faculty of Medicine, Assiut University, Egypt.

\begin{abstract}
Leg or foot amputation is the removal of a leg, foot or toes from the body. The aim of the study was to evaluate the effect of applying for a rehabilitation program on knowledge, the physical and psychosocial function of patients had lower limb amputation. A convenience sample of sixty adult patients divided randomly into two groups (study group and control group). First tool "patient' assessment sheet" second tool "psychosocial adaptation tool" Results concluded that; (100\%) patients in both groups had an unsatisfactory level of knowledge about lower limb amputation at the time of admission. While post-operative and at the time of follow-up; control group still had an unsatisfactory level of knowledge and most of the study group patients became having a satisfactory level of knowledge. Conclusion: providing written program for patients was much more effective on the outcome and decrease complications of patients who had lower limb amputation than those patients in the control group who received resident's oral instructions. Recommendations: a nurse rehabilitator is of great value in both vascular surgery department and the outpatient clinic and a rehabilitation program is of great importance for the amputated patients.
\end{abstract}

\section{Keywords: Amputation, Rehabilitation Program \& Psychosocial Adaptation}

\section{Introduction}

Amputation is the removal of one or more parts of the body and can be as a result of unprecedented havoc or natural disasters; like accidents, earthquakes of major intensity, terrorism and war, or carried out due to medical reasons with the motive to improve health outcomes and quality of life (QoL) of patients. In cancer patients, it is performed as a lifesaving procedure to protect them from the further malignancy of the body part or to other parts of the body. (Gallagher et al., 2011)

The indications for lower limb amputation (LLA) are largely Fontaine stages III or IV secondary to vascular occlusive disease, particularly in patients with diabetes mellitus (DM). The costs of limb amputation can be excessive in terms of initial hospital care, rehabilitation and ongoing community support, and this is especially so when patients can no longer cope independently in the community and may require long-term institutional care.( Peach et al., 2012)

Research has shown that the incidence of LLA is up to 8-15 times higher in diabetic patients compared to non-diabetic patients and that up to $70 \%$ of people die within 5 years of having an amputation as a result of diabetes. Further, the number of people with diabetes in the UK has increased from 1.4 million to 2.9 million since 1996 and is likely to reach 5 million by 2025 . It is also estimated that there are over threequarters of a million people in the UK with undiagnosed diabetes and this may not become apparent until their first admission with nonsalvageable lower limb sepsis. (Schanzer and Conte, 2013)

The prevalence of lower extremity vasculopathy is varied based on the method used to detect the vasculopathy. In this regard, the prevalence of peripheral vascular disease in the Arab population ranges between $50-78.7 \%$. (Almoutaz et al., 2011) Patient rehabilitation following lower limb amputation is essential to provide optimum patient outcomes and to improve the amputee's quality of life (QoL). The age of the patient and the stump length or level of amputation emerge as dominant factors affecting the outcome of rehabilitation. The psychological state of the individual is equally important in understanding the total wellbeing of the patients .early recognition and treatment of psychological morbidity seem to be important in preventing long-term disabilities in amputees. (Jasmine, 2013)

Multidisciplinary rehabilitation following lower limb amputation plays an important role in restoring function for activities of daily living, work, and recreation. Amputee rehabilitation service models 
and clinical practice guidelines for prosthetic prescription vary widely throughout the world and have been developed largely from expert consensus. In Western Australia, patients achieve independent transfers and wheelchair mobility during inpatient rehabilitation while prosthetic gait retraining is performed as an outpatient service. (Roffman et al., 2011)

Significance of the study

Major limb amputation impacts multiple aspects of an individual's life: body image, self-care activities, mobility, psychosocial health, vocational, and vocational opportunities. Successful rehabilitation allows the individual with an amputation to return to their highest level of activity and function. 307 patients had lower limb amputation in the vascular surgery department at Assiut university hospital in 2012. (Assiut University Hospital statistics record, 2012).

\section{Aims of the study}

- To determine the level of knowledge for patients had lower limb amputation before the implementation of the rehabilitation program.

- To develop the effect of implementing a rehabilitation program on knowledge, physical and psychosocial function of patients had lower limb amputation.

- To evaluate patients for prosthesis fitting through exercises program.

Research hypothesis

To fulfill the aim of the study the following research hypothesis were formulated:

1. The post mean knowledge and practice scores of patients who will be exposed to the rehabilitation program will be higher than their pre mean knowledge and practice scores.

2. The mean scores of physical and psychosocial adjustment of the study group will be higher than mean scores of functional and psychosocial adjustment of the control group.

3. Prosthesis fitting for study group will be better than prosthesis of the control group.

\section{Subjects \& method}

\section{Research design}

Quasi - experimental research design will be utilized to conduct this study

\section{Technical design}

\section{Setting}

This study was carried out in the vascular surgery department, outpatient clinics of the vascular surgery, physiotherapy department at Assiut University Hospital.

\section{Subjects}

- Sixty adult patients with lower limb amputation divided randomly into two groups (study group and control group) thirty for each group.

- Both sexes (adult males and females)

Tools for data collection

two tools for data collection was used to achieve the purpose of the current study

Tool I: "Patient's structured assessment tool"

This tool was constructed after reviewing the relevant literature: (Alice Rich, 2008, VA/DOD, 2008, Mahoney \& Barthel, 1965, Midwood, et al., 2004). It will be developed by the researcher to assess patients. This tool will consist of the following seven parts

Part one: demographic data for the patients as (name, age, gender, occupation, level of education, residence, date of admission and date of discharge)

Part two: Medical data including Medical diagnosis, affected side, present and past health history. vascularity color, sensation and movement.

Part three: it included pre-operative assessment of each body systems (integumentary, nervous, respiratory, cardiovascular, musculoskeletal, nutrition, metabolism) in addition to vital signs, laboratory investigation, and imaging studies.

Part four: it included post-operative assessment vital signs, pain, nutrition, wound categories and activities of daily living through Barthel index scale. It used ten variables describing activities of daily living (Mobility (on level surfaces, Stairs, Transfers (bed to chair and back), Toilet use, Bladder, Bowels, Dressing, Grooming, Bathing, Feeding) (Mahony \& Barthel, 1965).

Part five: it included periprosthetic assessment after two months

- Assessment for the function of the contralateral limb. Which include sensory deficit, motor deficit, and peripheral pulse. ( VA/DOD, 2008,CORE 6)

- Assessment for baseline functions of the affected limb. Which include a range of motion.( VA/DOD, 2008,CORE 7)

- Barthel index scale for assessing activities of daily living.

Part six: it included assessment of early complications of patients who had lower limb amputation as follow (phantom pain, non-healing of an amputation stump, stump infection, stump hematoma, pulmonary embolism and DVT, flexion contracture, bleeding and death)

Part seven: this tool was administered by the researcher to the patients' for answering all its components (pre / post immediately and after 2 months). 
The total number of questions was 13. It included assessment of patient's knowledge about lower limb amputation by open end questions as the following:

- Patients' knowledge about lower limb amputation. it consisted of 5 questions

- Patients' knowledge about post-operative care for lower limb amputation. It consisted of 8 questions.

Scoring system of tool (I)

Scoring system of Barthel index scale, full credits have scored (100) when patient does not need minimal help or supervision during performance and physically independent, while a score of (75-90) is given when patient mildly disabled, subsequently, a score of (50-70) is given when patient moderately disabled, while a score of (25-45) severely disabled and a score of (0-20) is given when patient very severely disabled and cannot perform activities of daily living. (Mahony \& Barthel, 1965).

The scoring system for patients ' knowledge was (28) degrees. A score of two was given for complete correct answer, one was given for incomplete correct answer and zero was for an incorrect answer. Patients who obtained less than $50 \%$ were considered having an unsatisfactory level of knowledge. While those who obtained more than $50 \%$ were considered having a satisfactory level of knowledge.

\section{Tool II: Psychosocial adaptation Tool (PAIS)}

Interview to assess psychosocial adjustment to illness scale by application of the (PAIS) tool "Derogatis $\boldsymbol{\&}$ Leonard 1986". It was developed and translated into the Arabic language. The PAIS is comprised of 33 questions, which are divided into 7 domains of psychosocial adjustment, the questions are posed to the patient in a semi-structure interview format, with responses rated 4 -point scale. The PAIS is designed to be completed as an integral aspect of a personal interview with the respondent, conducted by a trained health care professional or interviewer. The researcher was modified PAIS scale through deleting two domains Sexual Relationships and Extended Family Relationships according to expertise' opinion.

The five domains of adjustment:

- Section 1: Healthcare orientation

- Section 2: Vocational environment

- Section 3: Domestic environment

- Section 4: social environment

- Section 5: psychological distress

Scoring system of tool (II)

Each PAIS item is rated on a 4-point (0 thru 3) scale of adjustment, with higher ratings indicating poorer adjustment status. On the PAIS scale, the direction is alternated on every other item to help reduce position response biases.

\section{( Derogatis \& Leonard 1986)}

\section{Rehabilitation program}

This tool was developed by the researcher based on health and teaching needs gathered from control and study groups. The aim of it was to enable patients who had lower limb amputation to be knowledgeable about their condition in order to prevent, minimize, or retard possible complications that may affect their adjustment to living. It was formulated and introduced to the patients in the form of sessions, the contents of the program was developed by researcher and revised by experts in the medical and nursing fields. It consisted of the following:

- Information about the definition of amputation, causes types of lower limb amputation, signs, and symptoms, complications of lower limb amputation.

- Pre-operative rehabilitation phase

- 2, post-operative rehabilitation phase

- Preprosthetic phase

Methods

The study was conducted through:

- Data were collected at the vascular surgery department, outpatient clinics of the vascular surgery\&physiotherapy department at Assiut University Hospital during the period from March 2014 to November 2014.

- The study tools and rehabilitation program were formulated after a review of the literature.

- the content validity was done by 5 expertise (three vascular surgeon 'specialists) from the surgical field\& (two nursing staff) from the medicalsurgical nursing

- An official permission was obtained from the head of vascular surgery department and the head of the physiotherapy department

- Patient's agreement for voluntary participation was obtained after the purpose and nature of the study were explained.

- Data were assured confidentiality and anonymity and were collected using the pre-mentioned study tools.

- A pilot study was conducted on $10 \%$ (6) of patients to examine the feasibility of the study and clarity of the tools.

- The effect of implementing the rehabilitation program on patient's knowledge and practice regarding lower limb amputation and the incidence of postoperative complications was evaluated.

- After diagnosing the patient as lower limb amputation and he / she is admitted to vascular surgery department, the researcher meet with each patient individually, the study and its aims are explained to the patient.

- For the control group; after taking the patient oral agreement for voluntary participation in the study, 
the researcher then fills the patient's structured assessment sheet and psychosocial adaptation scale.(pre-operative and immediately postoperative).

- After the patient's discharge from the hospital, the researcher meets the patient for follow-up in the vascular outpatient clinic (during his/her first visit $\{2$ weeks after the surgery\}, and then two months post lower limb amputation for re-evaluating the patient's condition.

- For the study group; after filling the patient's structured assessment tool, the researcher explains to the patient the rehabilitation program preoperative and post-operative in the following sequence:

- The rehabilitation program were administered to the patient in three sessions, the duration of each session was about one hour, including 15 minutes for discussion and feedback.

- First session: the researcher started by introducing herself to the patients telling them the aim of the meeting, orient patients regarding the rehabilitation program. Contents of this session include anatomy and physiology of peripheral arterial system, causes of amputation, types and levels of lower limb amputation.

- Second session: summary about what has been discussed in a previous session, objectives of the new session, and contents of this session includes: pre-operative preparation and post-operative rehabilitation that involves correct position for the stump, exercises for below knee and above knee amputation and how to use assistive devices. The session ended by a summary of its content and feedback from the patients. Many patients were cooperative and interested in a given topic and asked to continue the program.

- Third session: summary about what has been discussed in a previous session, objectives of the new session, and contents of this session include: complications of lower limb amputation and periprosthetic rehabilitation that involves how to care of the stump in the home, exercises that strength upper extremities follow up instructions and prepare the patient to use prosthesis.

- The session ended by a summary of its content and feedback from the patients through discussion and asking questions.

- Each patient in the study group obtained a copy of the rehabilitation booklet.

The evaluation was carried out through introducing a tool (I ) and tool ( II) for all studied sample "both control and study group" to distinguish between control and study group and between the initial assessment of studied group and their assessment at the time of follow-up after two months after application of rehabilitation program. 


\section{Results}

Table (1): Distribution of studied sample (both control and study groups) as regarding their demographic characteristics.

\begin{tabular}{|c|c|c|c|c|c|}
\hline \multirow[t]{2}{*}{ Characteristics } & \multicolumn{2}{|c|}{$\begin{array}{c}\text { Study } \\
(\mathbf{n}=30)\end{array}$} & \multicolumn{2}{|c|}{$\begin{array}{c}\text { Control } \\
(\mathrm{n}=30)\end{array}$} & \multirow[t]{2}{*}{ P-value } \\
\hline & No. & $\%$ & No. & $\%$ & \\
\hline \multicolumn{5}{|l|}{ Age } & \multirow{4}{*}{0.271} \\
\hline$<50$ years & 4 & 13.3 & 5 & 16.7 & \\
\hline $50-<60$ years & 14 & 46.7 & 8 & 26.7 & \\
\hline$\geq 60$ years & 12 & 40.0 & 17 & 56.7 & \\
\hline Mean \pm SD & \multicolumn{2}{|c|}{$56.27 \pm 6.66$} & \multicolumn{2}{|c|}{$55.10 \pm 11.93$} & 0.642 \\
\hline \multicolumn{5}{|l|}{ Sex } & \multirow{3}{*}{0.438} \\
\hline Male & 14 & 46.7 & 17 & 56.7 & \\
\hline Female & 16 & 53.3 & 13 & 43.3 & \\
\hline \multicolumn{5}{|l|}{ Marital status } & \multirow{5}{*}{0.247} \\
\hline Single & 2 & 6.7 & 1 & 3.3 & \\
\hline Married & 23 & 76.7 & 17 & 56.7 & \\
\hline Divorced & 1 & 3.3 & 2 & 6.7 & \\
\hline Widow & 4 & 13.3 & 10 & 33.3 & \\
\hline \multicolumn{5}{|l|}{ Educational level } & \multirow{4}{*}{0.242} \\
\hline Not educated & 23 & 76.7 & 24 & 80.0 & \\
\hline Secondary & 7 & 23.3 & 4 & 13.3 & \\
\hline University & 0 & 0.0 & 2 & 6.7 & \\
\hline \multicolumn{5}{|l|}{ Occupation } & \multirow{6}{*}{0.222} \\
\hline Employer & 1 & 3.3 & 3 & 10.0 & \\
\hline Housewife & 15 & 50.0 & 12 & 40.0 & \\
\hline Retired & 6 & 20.0 & 5 & 16.7 & \\
\hline Does not work & 8 & 26.7 & 6 & 20.0 & \\
\hline Farmer & 0 & 0.0 & 4 & 13.3 & \\
\hline \multicolumn{5}{|l|}{ Residence } & \multirow{3}{*}{$0.010^{*}$} \\
\hline Urban & 4 & 13.3 & 13 & 43.3 & \\
\hline Rural & 26 & 86.7 & 17 & 56.7 & \\
\hline \multicolumn{5}{|l|}{ Hospital stay } & \multirow{3}{*}{0.390} \\
\hline$<3$ days & 23 & 76.7 & 20 & 66.7 & \\
\hline$\geq 3$ days & 7 & 23.3 & 10 & 33.3 & \\
\hline Mean \pm SD & \multicolumn{2}{|c|}{$2.90 \pm 1.03$} & \multicolumn{2}{|c|}{$2.83 \pm 0.83$} & 0.784 \\
\hline
\end{tabular}

Table (2): Distribution of activities of daily living measured by Barthel index in post-operative and follow-up for both group.

\begin{tabular}{|l|c|c|c|c|c|c|c|c|}
\hline \multirow{2}{*}{\multicolumn{1}{c|}{ Barthel index }} & \multicolumn{4}{c|}{ Study } & \multicolumn{4}{c|}{ Control } \\
\cline { 2 - 10 } & \multicolumn{2}{|c|}{ Post } & \multicolumn{2}{c|}{ Follow-up } & \multicolumn{3}{c|}{ post } & \multicolumn{2}{c|}{ Follow-up } \\
\cline { 2 - 10 } & No. & \% & No. & \% & No. & \% & No. & \% \\
\hline Very severely disabled & 23 & 76.7 & 0 & 0.0 & 21 & 70.0 & 5 & 18.5 \\
\hline Severely disabled & 5 & 16.7 & 5 & 17.2 & 8 & 26.7 & 15 & 55.6 \\
\hline Moderately disabled & 2 & 6.7 & 15 & 51.7 & 1 & 3.3 & 4 & 14.8 \\
\hline Mildly disabled & 0 & 0.0 & 9 & 31.0 & 0 & 0.0 & 2 & 7.4 \\
\hline Physical independent & 0 & 0.0 & 0 & 0.0 & 0 & 0.0 & 1 & 3.7 \\
\hline
\end{tabular}


Table (3): Distribution of studied sample (both control and study groups) as regarding complications of lower limb amputation.

\begin{tabular}{|l|c|c|c|c|c|}
\hline \multirow{2}{*}{\multicolumn{1}{|c|}{ Complications }} & \multicolumn{2}{c|}{ Study } & \multicolumn{2}{c|}{ Control } & \multirow{2}{*}{ P-value } \\
\cline { 2 - 6 } & No. & $\%$ & No. & \% & \\
\hline Phantom pain & 0 & 0.0 & 1 & 3.3 & 0.313 \\
\hline Non-healing of an amputation stump & 4 & 13.3 & 5 & 16.7 & 0.718 \\
\hline Stump infection & 8 & 26.7 & 0 & 0.0 & $0.008^{*}$ \\
\hline Stump hematoma & 1 & 3.3 & 2 & 6.7 & 0.554 \\
\hline Pulmonary embolism and DVT & 0 & 0.0 & 0 & 0.0 & -- \\
\hline Flexion contracture & 0 & 0.0 & 0 & 0.0 & -- \\
\hline Bleeding & 8 & 26.7 & 9 & 30.0 & 0.774 \\
\hline Death & 1 & 3.3 & 4 & 13.3 & 0.350 \\
\hline None & 16 & 53.3 & 13 & 43.3 & 0.438 \\
\hline
\end{tabular}

Table (4): Total score of patients' knowledge for both group (study and control) about lower limb amputation.

\begin{tabular}{|c|c|c|c|c|c|c|c|c|c|c|c|c|c|c|}
\hline & \multicolumn{6}{|c|}{ Study } & \multirow{3}{*}{ P-value } & \multicolumn{6}{|c|}{ Control } & \multirow{3}{*}{$\begin{array}{c}P- \\
\text { value }\end{array}$} \\
\hline & \multicolumn{2}{|c|}{ Pre } & \multicolumn{2}{|c|}{ Post } & \multicolumn{2}{|c|}{ Follow-up } & & \multicolumn{2}{|c|}{ Pre } & \multicolumn{2}{|c|}{ Post } & \multicolumn{2}{|c|}{ Follow-up } & \\
\hline & No. & $\%$ & No. & $\%$ & No. & $\%$ & & No. & $\%$ & No. & $\%$ & No. & $\%$ & \\
\hline \multicolumn{7}{|c|}{ Knowledge about lower limb amputation } & \multirow{3}{*}{$0.000 *$} & & & & & & & \multirow{3}{*}{0.286} \\
\hline Unsatisfactory & 20 & 66.7 & 0 & 0.0 & 0 & 0.0 & & 25 & 83.3 & 24 & 88.9 & 26 & 96.3 & \\
\hline Satisfactory & 10 & 33.3 & 30 & 100.0 & 29 & 100.0 & & 5 & 16.7 & 3 & 11.1 & 1 & 3.7 & \\
\hline \multicolumn{7}{|c|}{ Post-operative knowledge of lower limb amputation } & \multirow{3}{*}{$0.000 *$} & & & & & & & \multirow{3}{*}{0.138} \\
\hline Unsatisfactory & 30 & 100.0 & 0 & 0.0 & 0 & 0.0 & & 30 & 100.0 & 26 & 96.3 & 24 & 88.9 & \\
\hline Satisfactory & 0 & 0.0 & 30 & 100.0 & 29 & 100.0 & & 0 & 0.0 & 1 & 3.7 & 3 & 11.1 & \\
\hline \multicolumn{7}{|l|}{ Total knowledge } & \multirow{3}{*}{$0.000 *$} & & & & & & & \multirow{3}{*}{0.194} \\
\hline Unsatisfactory & 30 & 100.0 & 0 & 0.0 & 0 & 0.0 & & 30 & 100.0 & 25 & 92.6 & 24 & 88.9 & \\
\hline Satisfactory & 0 & 0.0 & 30 & 100.0 & 29 & 100.0 & & 0 & 0.0 & 2 & 7.4 & 3 & 11.1 & \\
\hline
\end{tabular}

Table (5) comparison between mean score of control and study groups regarding their level of knowledge about lower limb amputation.

\begin{tabular}{|c|c|c|c|c|c|c|c|c|}
\hline & \multicolumn{3}{|c|}{ Study } & \multirow{2}{*}{ P-value } & \multicolumn{3}{|c|}{ Control } & \multirow{2}{*}{ P-value } \\
\hline & Pre & Post & Follow-up & & Pre & Post & Follow-up & \\
\hline \multicolumn{4}{|c|}{ Knowledge about lower limb amputation } & \multirow{3}{*}{$0.000 *$} & & & & \multirow{3}{*}{0.783} \\
\hline Mean \pm SD & $5.87 \pm 1.41$ & $11.83 \pm 0.46$ & $10.31 \pm 0.81$ & & $5.50 \pm 1.07$ & $5.22 \pm 1.18$ & $5.37 \pm 2.03$ & \\
\hline Range & $3.0-8.0$ & $10.0-12.0$ & $9.0-12.0$ & & $4.0-9.0$ & $4.0-8.0$ & $3.0-8.0$ & \\
\hline \multicolumn{4}{|c|}{ Post-operative knowledge of lower limb amputation } & \multirow{3}{*}{$0.000^{*}$} & & & & \multirow{3}{*}{0.694} \\
\hline Mean \pm SD & $2.50 \pm 1.57$ & $13.27 \pm 1.05$ & $12.76 \pm 1.21$ & & $3.07 \pm 1.48$ & $4.11 \pm 1.25$ & $3.66 \pm 1.15$ & \\
\hline Range & $0.0-5.0$ & $11.0-14.0$ & $9.0-14.0$ & & $0.0-6.0$ & $0.0-5.0$ & $0.0-5.0$ & \\
\hline \multicolumn{4}{|c|}{ Total knowledge } & \multirow{3}{*}{$0.000 *$} & & & & \multirow{3}{*}{0.375} \\
\hline Mean \pm SD & $8.37 \pm 2.17$ & $25.10 \pm 1.24$ & $23.07 \pm 1.49$ & & $8.57 \pm 2.01$ & $9.22 \pm 2.35$ & $8.79 \pm 1.99$ & \\
\hline Range & $4.0-12.0$ & $22.0-26.0$ & $19.0-25.0$ & & $4.0-13.0$ & $3.0-14.0$ & $4.0-13.0$ & \\
\hline
\end{tabular}

Table (6): Mean score level of psychosocial adjustment of study group before and after application of rehabilitation program.

\begin{tabular}{|c|c|c|c|c|}
\hline psychosocial adjustment & Pre & Post & Follow-up & P-value \\
\hline \multicolumn{4}{|l|}{ Healthcare orientation } & \multirow{3}{*}{$0.000 *$} \\
\hline Mean \pm SD & $14.40 \pm 1.75$ & $8.80 \pm 2.31$ & $7.93 \pm 2.49$ & \\
\hline Range & $11.0-18.0$ & $1.0-13.0$ & $0.0-13.0$ & \\
\hline \multicolumn{4}{|l|}{ Vocational environment } & \multirow{3}{*}{$0.008^{*}$} \\
\hline Mean \pm SD & $17.00 \pm 2.15$ & $15.00 \pm 1.57$ & $18.00 \pm 2.20$ & \\
\hline Range & $15.0-17.0$ & $14.0-15.0$ & $16.0-18.0$ & \\
\hline \multicolumn{4}{|l|}{ Domestic environment } & \multirow{2}{*}{$0.000 *$} \\
\hline Mean \pm SD & $11.45 \pm 3.48$ & $9.53 \pm 2.13$ & $8.93 \pm 2.05$ & \\
\hline
\end{tabular}




\begin{tabular}{|c|c|c|c|c|}
\hline psychosocial adjustment & Pre & Post & Follow-up & P-value \\
\hline Range & $2.0-15.0$ & $5.0-14.0$ & $4.0-15.0$ & \\
\hline \multicolumn{4}{|l|}{ Social environment } & \multirow{3}{*}{$0.000 *$} \\
\hline Mean \pm SD & $10.60 \pm 2.53$ & $5.86 \pm 1.79$ & $5.86 \pm 1.92$ & \\
\hline Range & $7.0-16.0$ & $0.0-8.0$ & $0.0-9.0$ & \\
\hline \multicolumn{4}{|l|}{ Psychological distress } & \multirow{3}{*}{$0.000 *$} \\
\hline Mean \pm SD & $10.55 \pm 4.27$ & $5.83 \pm 2.68$ & $5.24 \pm 1.43$ & \\
\hline Range & $0.0-15.0$ & $0.0-12.0$ & $1.0-7.0$ & \\
\hline
\end{tabular}

Table (1): Showed that more than half $(56.7 \%)$ of control group their age was sixty and more while more than two fifths $(46.7 \%)$ of the study group was fifty to less than sixty. Regarding sex, it was found that more than half $(53.3 \%)$ of the study group was female compared to $(43.3 \%)$ in the control group. It was found that the highest percentages in both groups (study and control) married, illiterate, housewife and live in rural area. Regarding hospital stay, it was found that the highest percentages in both groups (study and control) stay in hospital less than 3 days.

Table (2): It is clear from this table that there is an increase in patient's activities of daily living measured by Barthel index after application of program than the control group. This appears through $(31 \%)$ improved mildly disabled in study group while more than half $(55.6 \%)$ severely disabled in the control group.

Table (3): Illustrated that according to control group, there were five $(16.7 \%)$ patients had nonhealing of an amputation stump, nine $(30 \%)$ patients had to bleed and thirteen $(43.3 \%)$ patients had none complications. While, in the study group, there were eight $(26.7 \%)$ patients had stump infection, eight $(26.7 \%)$ patients had bleeding and sixteen $(53.3 \%)$ patients had none complication.

Table (4): Showed that all patients in both groups (control and study) had an unsatisfactory level of knowledge about lower limb amputation at the time of admission. While post-operative and at the time of follow-up; control group still had an unsatisfactory level of knowledge and most of the study group patients became having a satisfactory level of knowledge.

Table (5): Illustrated that the mean score level of knowledge for the control group was very poor at the time of admission, postoperative and at the time of follow-up regarding all items of knowledge. While in study group the mean score level of knowledge was poor before application of rehabilitation program while after application of program their level of knowledge of all items improved at post-operative and follow-up.

Table (6): Illustrated that there was a significant difference in patients' psychosocial adjustment in the area of health care orientation, vocational environment, domestic environment, social environment and psychological distress. There was an improvement of mean score of health orientation from (14.40-8.80-7.93), also, as regard domestic environment there was an improvement (11.45-9.538.93 ), as regard social environment there was an improvement from (10.60-5.86-5.86) , as regard psychological distress there was an improvement (10.55- 5.83 - 5.24 )while in vocational environment there was an improvement post-operative and decreased improvement in follow-up .

\section{Discussion}

The current study revealed that more than half of the study group was female compared to $(43.3 \%)$ in the control group. This study finding was in line with a study conducted at Rheumatology and Rehabilitation Department at Minia University Hospital by Mohamed, (2014) entitled as Strategies of Daily Living Rehabilitative Activities for Post-Stroke Patients at Minia University Hospital. Which revealed that; more than half of study group were female compared to $(46.7 \%)$ in the control group.

The result of the present study revealed that more than half of control group their age was sixty and more while more than two fifth of the study group was fifty to less than sixty. This result agreed with Carmona et al., (2005) who stated that the rate of lower limb amputation varied from 1.8 to 11.4 /10000 patients /year, increased with age.

In the current study; it was found that the highest percentages in both groups (study and control) married, illiterate, housewife and live in rural area. Regarding hospital stay, it was found that the highest percentages in both groups (study and control) stay in hospital less than 3 days. This study finding was supported by Mahmoud, (2010) who carried out a study at the orthopedic outpatient clinic of Assiut University Hospital entitled as "The effect of Rehabilitation program on self-care of a patient with knee osteoarthritis which revealed that more than two third of study and control group were illiterate, housewife and married. As regarding hospital stay, this study disagreed with Awori \& Ating'a, (2007) who stated that hospital stay of patients ranged from 9 to 58 days with the mean duration of 22.4 days. The 
majority of patients (108: 66.7\%) had a good recovery.

The present study reported that increase in patient's activities of daily living measured by Barthel index after application of program than the control group. This appears through (31\%) improved mildly disabled in study group while more than half $(55.6 \%)$ severely disabled in the control group. Gallagher et al., (2011) he was found that restrictions were most commonly experienced in the areas of sports and physical recreation, leisure, and cultural activities, and employment. These findings indicate that the loss of a limb has a negative impact on people"s level of participation, thus demonstrating the importance of including this aspect of functioning in examinations of disability among persons with amputations.

The present study illustrated that according to control group, there were five (16.7\%) patients had nonhealing of an amputation stump, nine (30\%) patients had to bleed and thirteen $(43.3 \%)$ patients had none complications. While, in the study group, there were eight $(26.7 \%)$ patients had stump infection, eight $(26.7 \%)$ patients had bleeding and sixteen $(53.3 \%)$ patients had none complication.

Stone (2006) reported that Lower limb amputation is often performed in patients who have co-morbidities associated with reduced wound healing ability and predisposition to infection, the commonest of these being old age, diabetes mellitus, smoking, ongoing bacterial colonization and underlying vascular disease leading to poor tissue perfusion. Wound infection following lower limb amputation ultimately leads to a longer hospital stay, which in turn leads to greater risk of secondary morbidities such as hospital-acquired infections or more serious medical complications. For this reason, it is vital the postoperative wound is reviewed in a timely fashion with an objectively documented assessment. Postoperative antibiotic prophylaxis needs to be considered if the patient is at a high risk of infection, if not in all patients following limb amputations.

Burke \& Elizabeth, (2012) emphasized that after amputation, patients spend more time sitting, the remaining joints of your leg, and even your back, will spend more time bent or flexed. Too much of this can cause problems for your muscles and joints because they get used to being in a shortened position and you may develop a contracture.

An extensive study of 959 lower limb amputations by looked at post-operative morbidity and mortality; and recorded postoperative wound infection rates of $5.5 \%$ and $6.7 \%$ for below knee amputations (BKAs) and above knee amputations(AKAs). This reported by Aulivola, (2004)

The current study showed that all patients in both groups (control and study) had an unsatisfactory level of knowledge about lower limb amputation at the time of admission. While post-operative and at the time of follow-up; control group still had an unsatisfactory level of knowledge and most of the study group patients became having a satisfactory level of knowledge.

Chan et al., (2007) reported that education of patients and their families are aimed at the care and prevention of complications; it includes attention to limb care and inspection, limb wrapping, prosthetic care, stump care, foot care, and emergency care and monitoring for early signs of infection. Patient inspection of the limb is particularly important if the patient has a prosthesis, as this should not be done if there is any possibility of infection. Limb wrapping often needs to be done several times a day. The prosthetic will require daily cleaning and inspection to prevent infection and to allow for maximal use. Stump socks must be scrupulous.

The present study showed that the mean score level of knowledge for the control group was very poor at the time of admission, postoperative and at the time of follow-up regarding all items of knowledge. While in study group the mean score level of knowledge was poor before application of rehabilitation program while after application of program their level of knowledge of all items improved at post-operative and follow-up.

Louis, (2007) mentioned that patient teaching is important because the patient has the right to know and to be informed about diagnosis, the prognosis of illness, treatment options, risks associated with treatments. And assigned patient teaching to the professional nurse and rationalized the advantages of a well-designed comprehensive teaching plan that fit patients' unique learning needs that it reduces health care costs and improve the quality of care. As patient teaching help patients make informed decisions about their health care and to become healthier and more independent.

This study illustrated that there was a significant difference in patients' psychosocial adjustment in the area of health care orientation, vocational environment, domestic environment, social environment and psychological distress. There was an improvement of mean score of health orientation from (14.40-8.80-7.93), also, as regard domestic environment there was an improvement (11.45-9.53$8.93)$, as regard social environment there was an improvement from (10.60-5.86-5.86), as regard psychological distress there was an improvement (10.55- 5.83 - 5.24 )while in vocational environment there was an improvement post-operative and decreased improvement in follow-up.

. Olga \& Malcolm, (2004) Although depression and anxiety are relatively high up to 2 years post- 
amputation, they appear to decline thereafter to general population norms. However, social discomfort and body-image anxiety have also been found among some people with amputations, and these have been associated with increased activity restriction, depression, and anxiety. Factors associated with positive adjustment to limb loss include greater time since amputation, more social support, greater satisfaction with the prosthesis, active coping attempts, an optimistic personality disposition, a lower level of amputation in the case of lower limbs, and lower levels of phantom limb pain and stump pain.

\section{Conclusions}

The result of the present study concluded that; there is an increase in patient's activities of daily living measured by Barthel index after application of program than the control group. This appears through (31\%) improved mildly disabled in study group while more than half $(55.6 \%)$ severely disabled in the control group. All patients in both groups (control and study) had an unsatisfactory level of knowledge about lower limb amputation at the time of admission. While post-operative and at the time of follow-up; control group still had an unsatisfactory level of knowledge and most of the study group patients became having a satisfactory level of knowledge. There was a significant difference in patients ' psychosocial adjustment in the area of health care orientation between control and study group. There was no significant difference in patients' psychosocial adjustment in the area of vocational environment, domestic environment, social environment and psychological distress between control and study group.

\section{Recommendation}

\section{For patients}

- A continuous educational and rehabilitation program planned and offered on regular basis to amputated patients in vascular surgery department, outpatient clinic of the vascular surgery and physiotherapy department

- Increase patients' awareness about the importance of periodic check up to prevent developing any complications which can affect their quality of life.

\section{In services}

Providing a written rehabilitation instruction booklet is of great importance for the patients.

\section{For nurses}

- Periodically assessment of nurses' knowledge and practice in relation to a bundle of care of patients with lower limb amputation.
- Newly employed nurses in the vascular surgery department are required to successfully complete a test of a basic knowledge and skills before assuming independent responsibility for patient care.

For research

Replication of the current study on larger probability sample is recommended to generalize ability and wider utilization of the designed program.

- Establish an effective training program on the nursing intervention of post amputated patients' rehabilitation, should be well organized and equipped with necessary educational facilities for nurses.

\section{References}

1. Alice Rich R., (2008): pain scale, http://www.pudendal info/documents/comparative pain scale

2. Almoutaz Alkhier, Emad Elsharief \& Ali Alsharief (2011): The Diabetic Foot in the Arab World, The Journal of Diabetic Foot Complications, Volume 3, Issue 3, No. 3, Pages 55-61

3. Aulivola B., (2004): Major lower extremity amputation: outcome of a modern series. Arch Surg, 139 (4): 395-9.

4. Awori. K., \&Ating'a J., (2007): Lower limb amputation at the Kenyatta National Hospital, Nairobi. East Afr. Med J, 84(3):121-6.

5. Burke M., \& Elizabeth Cole, (2012): Exercises for People with Lower-Extremity Amputations. The Amputee Coalition organization.

6. Carmona G., Hoffmeyer P., Herrmann F., Vaucher J., Tschopp O., Lacraz A., (2005): Major lower limb amputations in the elderly observed over ten years: The role of diabetes and peripheral arterial disease. Diabetes and Metabolism 31(5):449-454

7. Chan, B., Witt. R., Charrow. A., Magee. A., Howard. R., Pasquina P., (2007): Mirror Therapy for Phantom Limb Pain. New England Journal of Medicine, 357(21), 2206-2207

8. Derogatis. L., \& Leonard R., (1986): The psychosocial adjustment to illness scale .volume 30(1) pp 77-91

9. Gallagher P., O'Donovan M., Doyle A., Desmond D., (2011): Environmental barriers, activity limitations and participation restrictions experienced by people with major limb amputation .sep: 35(3):278-284.national center for biotechnology information, US.national library of medicine

10. Louis. S., (2007): Health promotion throughout the lifespan, $7^{\text {th }}$ ed., Mosby company, 187p.p 
11. Jasmine. W., (2013): The relation among psychological and demographic factors in individuals with lower limb amputation. Amputation and depression, Trinity College Digital Repository. 10-200. http://digital repository .trincil.edu/theses/337.

12. Mahmoud M., (2010): The effect of rehabilitation program on self-care of patient with knee osteoarthritis, Doctor Degree, Adult nursing department, faculty of nursing, Assiut University

13. Mahoney. F., \& Barthel. D., (1965): Maryland state med journal functional evaluation. The Barthel index, pp 56:61

14. Midwood. K., Williams. L., Schwarzbowery. J., (2004): tissue repair and the dynamic of the extracellular matrix. The international journal of biochemistry \& cell biology.

15. Mohamed H., (2014): Strategies of Daily Living Rehabilitative Activities for Post-Stroke Patients at Minia University Hospital, Doctorate Degree, Adult Nursing (Medical- Surgical Nursing), Faculty of Nursing, Minia University

16. Olga H., \& Malcolm M., (2004): Psychosocial adjustment to lower-limb amputation: A review, Vol. 26, No. 14-15, Pages 837-850. Department of Psychology, Trinity College, University of Dublin, Dublin 2, Ireland malcolm.maclachlan@tcd.ie

17. Peach G., Griffin M., Jones K., Thompson M., \& Hinchcliffe R., (2012): Diagnosis and management of the peripheral arterial disease. British Medical Journal, 345(7870) 36-41.

18. Roffman C., Buchanan J., Allison G., (2011): Predictors of non-use of prostheses by people with lower limb amputation after discharge from rehabilitation: development and validation of clinical prediction rules. Journal of Physiotherapy60: 224-231

19. Schanzer A., \& Conte M., (2013): Critical Limb Ischemia. Current Treatment Options in Cardiovascular Medicine, 12 214-229.

20. Stone P., (2006): Factors affecting perioperative mortality and wound-related complications following major lower extremity amputations. Ann Vasc Surg, 20 (2): 209-216.

21. VA/DOD Employee education system in cooperation with the offices of quality \& performance and patient care services and the department of defense, (2008): clinical practice guideline for rehabilitation of lower limb amputation. 